\section{BMJ Open Respiratory Research}

\title{
Side effects of acetazolamide: a systematic review and meta-analysis assessing overall risk and dose dependence
}

\author{
Christopher N Schmickl (D) , ${ }^{1}$ Robert L Owens, ${ }^{1}$ Jeremy E Orr, ${ }^{1}$ \\ Bradley A Edwards, ${ }^{2,3}$ Atul Malhotra ${ }^{1}$
}

To cite: Schmickl CN, Owens RL, Orr JE, et al. Side effects of acetazolamide: a systematic review and metaanalysis assessing overall risk and dose dependence. BMJ Open Resp Res 2020;7:e000557. doi:10.1136/ bmjresp-2020-000557

- Additional material is published online only. To view please visit the journal online (http://dx.doi.org/10.1136/ bmjresp-2020-000557).

Received 4 January 2020 Revised 22 February 2020 Accepted 29 February 2020

\section{Check for updates}

(C) Author(s) (or their employer(s)) 2020. Re-use permitted under CC BY-NC. No commercial re-use. See rights and permissions. Published by BMJ.

${ }^{1}$ Department of Medicine, Division of Pulmonary, Critical Care and Sleep Medicine, University of California San Diego, La Jolla, California, USA

${ }^{2}$ Sleep and Circadian Medicine Laboratory, Department of Physiology, Monash University, Clayton, Victoria, Australia

${ }^{3}$ School of Psychological Sciences and Monash Institute of Cognitive and Clinical Neurosciences, Monash University, Clayton, Victoria, Australia

Correspondence to Dr Christopher N Schmickl; cschmickl83@gmail.com

\section{ABSTRACT}

Introduction Acetazolamide (AZM) is used for various conditions (eg, altitude sickness, sleep apnoea, glaucoma), but therapy is often limited by its side effect profile. Our objective was to estimate the risk of commonly reported side effects based on metaanalyses. We hypothesised that these risks are dosedependent.

Methods We queried MEDLINE/EMBASE (Medical Literature Analysis and Retrieval System Online/Excerpta Medica dataBASE) up until 04/10/2019, including any randomised placebo-controlled trial in which adults received oral AZM versus placebo reporting side effects. Eligibility assessment was performed by two independent reviewers. Data were abstracted by one reviewer who verified key entries at a second time point. For side effects reported by $\geq 3$ studies a pooled effect estimate was calculated, and heterogeneity assessed via $\mathrm{I}^{2}$; for outcomes reported by $\geq 5$ studies effect modification by total daily dose (EMbyTDD; $<400 \mathrm{mg} / \mathrm{d}$, $400-600 \mathrm{mg} / \mathrm{d},>600 \mathrm{mg} / \mathrm{d}$ ) was assessed via metaregression. For pre-specified, primary outcomes (paraesthesias, taste disturbances, polyuria and fatigue) additional subgroup analyses were performed using demographics, intervention details, laboratory changes and risk of bias.

Results We included 42 studies in the meta-analyses $\left(\mathrm{N}_{\text {subjects }}=1274 / 1211\right.$ in AZM/placebo groups). AZM increased the risk of all primary outcomes $(p<0.01$, $I^{2} \leq 16 \%$ and low-to-moderate quality of evidence for all)-the numbers needed to harm $\left(95 \% \mathrm{Cl} ; \mathrm{n}_{\text {studies }}\right)$ for each were: paraesthesias $2.3(95 \% \mathrm{Cl} 2$ to $2.7 ; n=39)$, dysgeusia $18(95 \% \mathrm{Cl} 10$ to $38, n=22)$, polyuria $17(95 \%$ Cl 9 to $49 ; n=22)$, fatigue $11(95 \% \mathrm{Cl} 6$ to $24 ; n=14)$. The risk for paraesthesias (beta $=1.8(95 \% \mathrm{Cl} 1.1$ to 2.9); $\left.P_{\text {EMbyTDD }}=0.01\right)$ and dysgeusia (beta $=3.1(95 \% \mathrm{Cl}$ 1.2 to 8.2); $P_{\text {EMbyTDD }}=0.02$ ) increased with higher AZM doses; the risk of fatigue also increased with higher dose but non-significantly (beta $=2.6(95 \% \mathrm{Cl} 0.7$ to 9.4$)$; $\left.P_{\text {EMbyTDD }}=0.14\right)$.

Discussion This comprehensive meta-analysis of lowto-moderate quality evidence defines risk of common AZM side effects and corroborates dose dependence of some side effects. These results may inform clinical decision making and support efforts to establish the lowest effective dose of AZM for various conditions.

\section{Key messages}

What is the key question?

- What is the risk of developing one of the common side effects of AZM and are these risks dose-dependent?

What is the bottom line?

- The numbers needed to harm for paraesthesias, dysgeusia, polyuria, fatigue ranged from 2 to 18 . The risk for paraesthesias, dysgeusia and possibly fatigue increase with higher AZM doses.

\section{Why read on?}

- Based on a large number of randomised, placebocontrolled trials from multiple disciplines, this article provides precise estimates in clinically relevant terms (number needed to harm) for various side effects including but not limited to the ones mentioned earlier.

\section{INTRODUCTION}

Acetazolamide (AZM) is a carbonic anhydrase (CA) inhibitor that has been used since the 1950 s for various medical conditions. ${ }^{1-7}$ For example, it is highly efficacious in treating glaucoma, ${ }^{89}$ preventing ${ }^{10-12}$-and possibly treating ${ }^{13}$ acute mountain sickness (AMS); however, side effects are common with some studies reporting an incidence of $80 \%-100 \%^{2} 14$ (especially paraesthesias, dysgeusia, polyuria and fatigue), which limits patients' tolerance and compliance. ${ }^{215}$ It has been postulated that some of the side effects may be related to the amount of metabolic acidosis caused by $\mathrm{AZM}^{16}$ (via renal bicarbonate wasting which reaches steady state within 1-2 days ${ }^{17}{ }^{18}$ ) and plasma drug levels that are affected by weight and renal function. ${ }^{19-21}$ Based on these and other data limited by small numbers and/or observational nature there has been a notion that some of the side effects may be dose-dependent (see online supplementary e-Table 1). ${ }^{11} 12$ This perception has 
led to substantial efforts to find the lowest effective dose to prevent AMS for which a review from 2012 suggested $250 \mathrm{mg} /$ day to be similarly effective as $750 \mathrm{mg} /$ day, ${ }^{11}$ although the number needed to treat was higher for the lower dose (number needed to treat (NNT) 6 (95\% CI 5 to 11$)$ vs 3 (95\% CI 3 to 5 )). Of note, this study provided only very limited, semi-quantitative information about four side effects based on data from five studies. However, informed decision making about whether to use AZM (and if so which dose) is based on weighing potential benefits against risks, and thus requires robust quantitative estimates for each. Furthermore, whether efforts to find the lowest effective dose of AZM for other conditions (eg, idiopathic intracranial hypertension and sleep apnoea) are warranted depends on whether side effects are dosedependent.

Our objective is to provide precise estimates for the risk of developing one of the common side effects of AZM and to assess systematically whether this risk is dosedependent. We assumed that the risk of most AZM side effects-unlike efficacy-is independent of the underlying condition for which it is used for and thus pooled data from trials using AZM for various conditions; we formally tested this assumption via meta-regression (see results).

\section{METHODS}

This review was performed according to a pre-specified study protocol (online supplementary e-Appendix 1) and following PRISMA-reporting guidelines (Preferred Reporting Items for Systematic Reviews and MetaAnalyses). ${ }^{22}$

\section{Patient and public involvement}

Patients were not involved in the design or execution of this study.

\section{Identification of studies}

We considered any randomised controlled trial (RCT) in which adult subjects were randomised to oral AZM versus placebo reporting side effects. We excluded trials with subjects who were non-human, non-adult, unable to report side effects reliably (eg, intubated), receiving haemodialysis (rationale: substantial impact on pharmacokinetics; high prevalence of dysgeusia, paraesthesias/neuropathy, fatigue; inability to assess polyuria); we further excluded trials lacking information about side effects, administering AZM as a non-PO formulation (eg, intravenously/inhaled), or giving AZM only in combination with another systemic intervention (precluding isolated assessment of the AZM effect).

We searched MEDLINE and EMBASE from inception until 04/10/2019, and reviewed reference lists of eligible and other seminal articles. The final search strategies were:
- MEDLINE: (Acetazolamide(Mesh) OR Acetazolamide(tiab)) AND (Randomised Controlled Trial(ptyp) AND Placebo)

- EMBASE: ('acetazolamide':ti,ab,kw OR 'acetazolamide'/ exp) AND ('placebo':ab,ti OR 'placebo'/exp) AND ('randomized controlled trial'/de)

We did not place any language restrictions. We contacted the authors of two foreign language articles 2324 without success, but subsequently were able to determine the ineligibility of these reports with the help of native speakers (see acknowledgements section).

\section{Eligibility assessment and data abstraction}

Titles and abstracts of retrieved records were screened independently by two authors (CNS and AM) with final eligibility assessment based on full-text articles applying above inclusion/exclusion criteria (disagreements resolved by discussion). Data from eligible studies were abstracted by CNS using a piloted Microsoft Excel form. To minimise the risk for data abstraction errors we utilised drop-down lists in Excel whenever possible and doublechecked all abstracted key data points at a second time point. We further employed sensitivity analyses to assess the impact of any decisions made during these stages (eg, imputation of zeroes in placebo arms of studies that only reported adverse events for the AZM group).

Abstracted data included demographics of study participants (eg, age, gender, body mass index (BMI)), intervention details (eg, AZM dose, days of administration, adjustment for renal function), ${ }^{19}$ pertinent labs (eg, $\mathrm{pH},{ }^{16} \mathrm{pCO}_{2} / \mathrm{HCO}_{3},{ }^{19}$ chloride $)^{20}$ and side effects (primary outcomes: paraesthesias, dysgeusia, polyuria, fatigue). For a full list of variables and their definitions see the study protocol (online supplementary e-Appendix 1) and the data set (online supplementary e-Table 2). For each side effect we collected the number of subjects who experienced that side effect at any time during the study's observation period versus those who did not in the AZM versus placebo group; for laboratory tests we collected the mean value in the AZM versus placebo arms (following study drug administration, ie, ignoring change from baseline).

\section{Risk of bias assessment}

Risk of bias was assessed as either low, high or unclear across five domains (selection, performance, detection, attrition, reporting) at the study level but the focus was on risk of bias with regard to the reported side effects, not the primary outcomes of the studies. Overall risk of bias was defined as the 'highest' level of bias across these five domains; its effect on the results was assessed by checking for significant effect modification via meta-regression.

\section{Statistical analysis}

Data preparations: Placebo arms that served as comparator for two AZM arms with different doses were divided evenly into halves to avoid double-counting of the control 
group (unit of analysis error) while allowing assessment of effect modification by AZM dose. ${ }^{1125}$ Studies that clearly stated that no events occurred in both the AZM and control arm were included into the primary analysis by adding a continuity correction of 0.5 to all cells (rationale: assuming dose dependency of side effects, low-dose AZM studies are more likely to have zero events in the intervention arms than high-dose AZM studies, while zero events in placebo arms are equally likely to occur in low and high-dose studies; thus exclusion of studies with zero-events in both arms would preferentially exclude low-dose trials and bias the risk estimate in low-dose AZM trials upwards, thereby reducing power to detect dose dependence) ${ }^{26}$

Risk of side effects: For all side effects reported by three or more studies we calculated a pooled effect estimate using Mantel-Haenszel methodology (rationale: we used fixed rather than random effects model to avoid small study bias). All analyses were performed using ORs due to their favourable mathematical properties compared with risk ratios; however, to aid interpretability, final results are also reported as risk ratios (calculated directly from the $\mathrm{ORs}$ as $\mathrm{RR}=\mathrm{OR} /(1-\mathrm{ACR} *(1-\mathrm{OR}))$ where assumed control risk (ACR) is estimated from the overall event rate across placebo arms) and NNT $(\mathrm{NNT}=1 / \mathrm{ACR}-((\mathrm{OR} * \mathrm{ACR}) /(1-\mathrm{ACR}+\mathrm{OR} * \mathrm{ACR})) \mathrm{I}) .{ }^{25} 27$ Heterogeneity was quantified by the $\mathrm{I}^{2}$ statistic and arbitrarily categorised as low $(<30 \%)$, moderate $(30 \%-50 \%)$ or high $(>50 \%)^{2528}$; in case of $\mathrm{I}^{2}>30 \%$ attempts were made to identify and adjust for sources of heterogeneity, and a random effects model was used instead (if $\mathrm{I}^{2}$ remained $>30 \%$ ).

Subgroup analysis: Dose dependency was assessed for all outcomes with a pooled effect estimate based on five or more studies by testing for effect modification by total daily dose via meta-regression (one study ${ }^{29}$ reported a total daily dose of $2500 \mathrm{mg}$ /day vs $125-1000 \mathrm{mg}$ /day in all others; to avoid results to be driven by this outlier we divided the total daily dose into a three-level categorical variable for the primary analyses [ie $<400 \mathrm{mg} /$ day, $400-600 \mathrm{mg} /$ day and $>600 \mathrm{mg}$ / day were picked to include commonly used doses while dividing studies in roughly equal numbers]). In addition, in sensitivity analyses we also assessed dosage as a linear variable. For primary outcomes (paraesthesias, dysgeusia, polyuria, fatigue) we further assessed effect modification by days of AZM administration, cumulative dose, patient/study characteristics, as well as changes in laboratory tests.

Extensive sensitivity analyses were performed to assess robustness of results for primary outcomes (eg, exclusion of studies with zero events in both arms and changes in model parameters). Publication bias was assessed via funnel plots and Egger's test.

All analyses (including tests for publication bias) were performed using STATA V.12.1 (StataCorp) with $\mathrm{p}<0.05$ denoting statistical significance.
Quality of evidence assessment

Quality of evidence for primary outcomes was assessed following Grading of Recommendations Assessment, Development and Evaluation guidelines.

\section{RESULTS}

\section{Included studies}

We identified a total of 53 studies $^{61529-77}$ reporting one or more side effects (figure 1). Seven references were identified through the search of reference lists $\left(5^{676878-80}\right.$ from, ${ }^{12} 1^{81}$ from, ${ }^{82}$ and $1^{3}$ from ${ }^{83}$; only $2^{6768}$ of these 7 met eligibility criteria and were included in this review). Two articles ${ }^{6}{ }^{42}$ reported two treatment arms administering different AZM doses versus a placebo control; thus each report contributed two studies for analyses. Table 1 provides an overview of the 42 studies included into quantitative analyses: about one third of participants in included trials were females, with a wide range of mean age (19-74 years) and BMI $\left(20-40 \mathrm{~kg} / \mathrm{m}^{2}\right)$; race was only reported in five studies in which the majority of subjects were white ( $79 \%$ vs $16 \%$ black vs $5 \%$ other). The majority of studies assessed the impact of AZM on acute/ chronic mountain sickness (48\%), intraocular pressure $(17 \%)$, or sleep disordered breathing (SDB, $10 \%)$, with remainder of conditions varying widely. About half of the studies queried the side effects actively and were judged as low $(24 \%)$ or unclear $(33 \%)$ risk of overall bias. On average, there were 30 participants in each AZM arm (range 6-118), receiving $542 \mathrm{mg}$ of AZM per day (range $125-4000 \mathrm{mg}$ ) for a total of 17 days (range 1-180 days). Renal function was taken into account by one third of trials, and $7 \%$ of trials provided some form of potassium supplementation (online supplementary e-Table 2 in the online supplement provides the full data set).

\section{Primary outcomes}

AZM increased the odds for all the primary outcomes (paraesthesias, ${ }^{61529-3437-4648-57596062-68 \text { dysgeusia, } 62931323537}$ 3842-46505255-586468 polyuria $629323437384042-45515254555861626768$ and fatigue 29 31-33 $3548505254-5868$ ) by 1.9-12.3 times (low-tomoderate quality of evidence). For paraesthesias, dysgeusia and fatigue the odds of side effects increased by 2-3 fold for each 1-step increase in total daily dose across the three categories $(400 \mathrm{mg}$ vs $400-600 \mathrm{mg}$ vs $>600 \mathrm{mg}$ ) in metaregression; however, the CI for fatigue included the 'null' of no increase in side effects with higher doses. There was no evidence for dose dependency of polyuria (table 2 and online supplementary e-Appendix 2).

In further subgroup analyses, the odds of side effects were 1.5-4 times higher in studies querying symptoms actively versus unclear/passively, but only the CI for dysgeusia excluded the null. There odds for fatigue were 1.4 times higher per $10 \%$ increase in the percentage of females but the CI was wide (0.9-2.1); furthermore, with the exception of paraesthesias odds were slightly higher with increasing AZM duration/cumulative dose but effect sizes were small and CIs all included the null (table 3). Of 


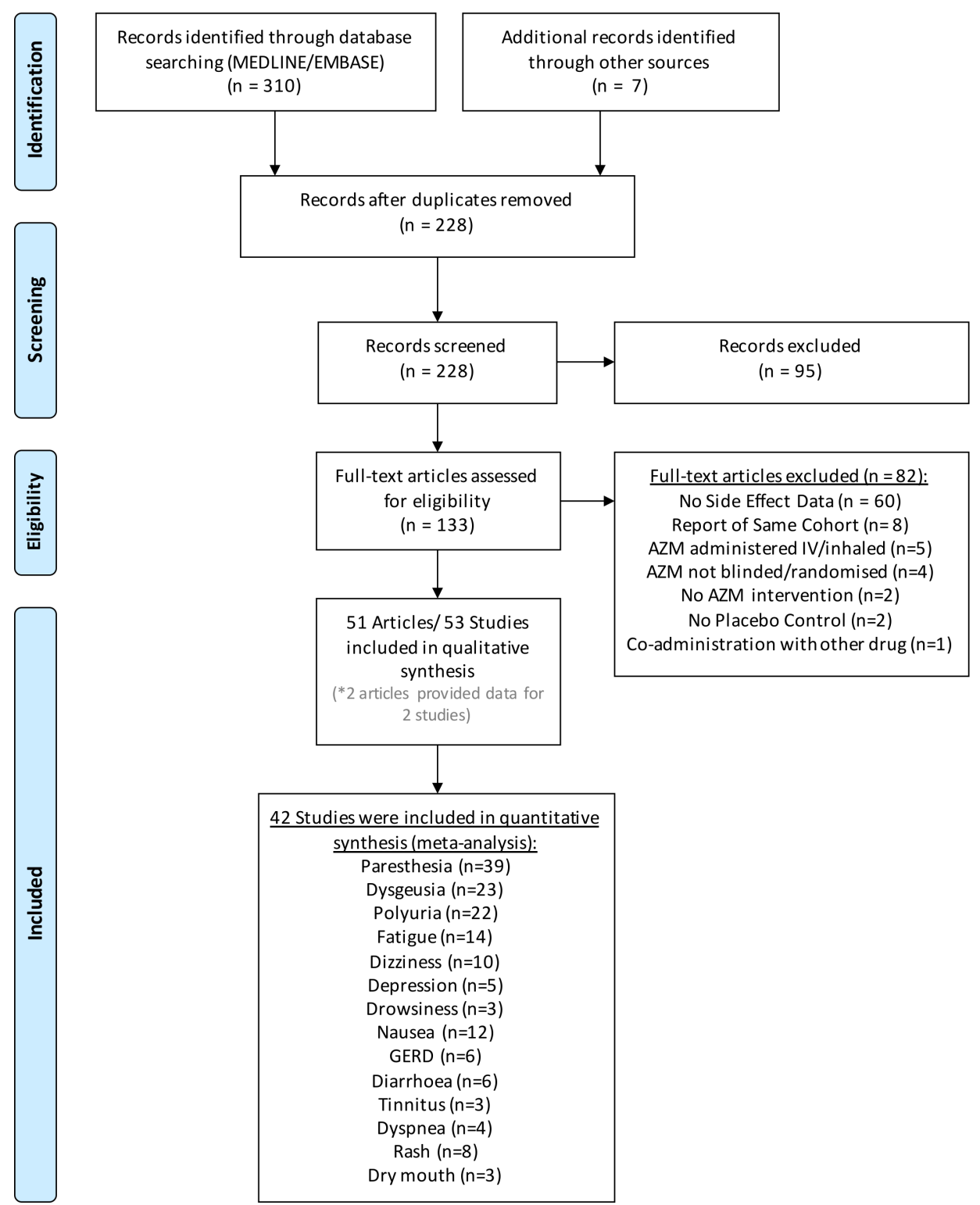

Figure 1 PRISMA (Preferred Reporting Items for Systematic Reviews and Meta-Analyses) flow chart. ${ }^{22}$ Most included studies provided data for several side effects. Seven records were identified by screening reference lists from eligible and seminal articles; two reports each provided data about two studies (for details see the text). AZM, acetazolamide; GERD, gastro-oesophageal reflux disease.

note, there was no evidence of effect modification by risk of overall bias.

The number needed to treat for harm (ie, number of patients needed to be treated for one additional patient to be harmed) ${ }^{27}$ ranged from 2.3 for paraesthesias to 18 for dysgeusia (table 4). Results were robust based on various sensitivity analyses and there was no evidence of publication bias (Egger's $\mathrm{p}>0.05$ for all; online supplementary e-Appendix 2).

\section{Secondary outcomes}

AZM increased the odds of nausea, ${ }^{29354350-5457616268}$ gastrooesophageal reflux disease, ${ }^{293840526768}$ diarrhoea ${ }^{2935445267}$ and depression ${ }^{2944525768}$ by 2.6-4 fold. Furthermore, AZM increased the odds of drowsiness, ${ }^{52} 5464$ tinnitus, ${ }^{29} 4448$ dyspnoea $^{29} 435367$ and dry mouth ${ }^{29} 4852$ by $2.3-4.7$ fold but the lower confidence limit just included the null; rash $^{29} 424445485254$ and dizziness ${ }^{29} 303538445053616468$ were slightly more common in AZM groups (ORs 1.7 and 1.2, respectively) but CIs were wide and included the null. There was no evidence of dose dependence for any of the secondary outcomes, but analyses were limited by small numbers of trials $(\mathrm{n}=5-12$; table 2$)$. The number needed to treat to cause one additional secondary side effect ranged from 12 for diarrhoea to 100 for dizziness (table 4). Side effects that were reported in less than three studies are shown in online supplementary e-Table 3: most notably hypokalaemia was reported in two studies ${ }^{29} 48$ (daily dose $500-4000 \mathrm{mg}$ ) occurring almost exclusively in the setting of concomitant therapy 
Table 1 Characteristics of studies included into quantitative analyses $(n=42)$

\begin{tabular}{|c|c|c|c|}
\hline Study characteristics & $\begin{array}{l}\text { Mean (SD) or } \\
\%\left(\mathrm{~N}_{\text {Studies }}\right)\end{array}$ & Range & $\mathbf{N}_{\text {Studies }}$ \\
\hline \multicolumn{4}{|l|}{ General } \\
\hline Age, years & $44(15)$ & 19 to 74 & 37 \\
\hline$\%$ female & $36(29)$ & 0 to 98 & 40 \\
\hline BMl, kg/m² & $27(5.6)$ & 20 to 40 & 11 \\
\hline Weight, kg & 75 (18) & 51 to 108 & 10 \\
\hline Height, cm & $165(5.4)$ & 160 to 174 & 6 \\
\hline Race & & & 5 \\
\hline White & $79.2(17)$ & 63 to 100 & \\
\hline Black & $16(13)$ & 0 to 30 & \\
\hline Other & $5.2(4.4)$ & 0 to 11 & \\
\hline Condition & & & 42 \\
\hline $\begin{array}{l}\text { Acute/chronic } \\
\text { mountain sickness }\end{array}$ & $48(20)$ & $\mathrm{Na}$ & \\
\hline $\begin{array}{l}\text { Sleep disordered } \\
\text { breathing }\end{array}$ & $10(4)$ & $\mathrm{Na}$ & \\
\hline $\begin{array}{l}\text { Ophthalmologic } \\
\text { condition (medical) }\end{array}$ & $10(4)$ & $\mathrm{Na}$ & \\
\hline $\begin{array}{l}\text { Ophthalmologic } \\
\text { surgery }\end{array}$ & 7 (3) & $\mathrm{Na}$ & \\
\hline Other* & $26(11)$ & $\mathrm{Na}$ & \\
\hline Diuretic use & & & 42 \\
\hline Yes & $12(5)$ & $\mathrm{Na}$ & \\
\hline Unclear/no & $88(37)$ & $\mathrm{Na}$ & \\
\hline $\begin{array}{l}\text { Query type (for side } \\
\text { effects) }\end{array}$ & & & 42 \\
\hline Active & $52(22)$ & $\mathrm{Na}$ & \\
\hline Unclear/passive & $48(20)$ & $\mathrm{Na}$ & \\
\hline Overall bias $†$ & & & 42 \\
\hline Low & $24(10)$ & $\mathrm{Na}$ & \\
\hline Unclear & $33(14)$ & $\mathrm{Na}$ & \\
\hline High & $43(18)$ & $\mathrm{Na}$ & \\
\hline \multicolumn{4}{|l|}{ Intervention } \\
\hline \multicolumn{4}{|l|}{ Acetazolamide } \\
\hline Total daily doseł, mg & $542(371)$ & 125 to $4000 \S$ & 42 \\
\hline $\begin{array}{l}\text { Total daily dose/kgf, } \\
\mathrm{mg} / \mathrm{kg}\end{array}$ & $6.9(4.6)$ & 3.1 to 23 & 15 \\
\hline $\begin{array}{l}\text { Total daily dose } \\
\text { (categorical) }\end{array}$ & & & 42 \\
\hline$<400 \mathrm{mg}$ & $29(12)$ & $\mathrm{Na}$ & \\
\hline $400-600 \mathrm{mg}$ & $50(21)$ & $\mathrm{Na}$ & \\
\hline$>600 \mathrm{mg}$ & $21(9)$ & $\mathrm{Na}$ & \\
\hline Doses per day & $1.8(0.7)$ & 1 to 4 & 42 \\
\hline $\begin{array}{l}\text { Days of administration } \\
\text { (continuous) }\end{array}$ & $17(32)$ & 1 to 180 & 42 \\
\hline $\begin{array}{l}\text { Days of administration } \\
\text { (categorical) }\end{array}$ & & & 42 \\
\hline$<3$ days & $26(11)$ & $\mathrm{Na}$ & \\
\hline 3 to 7 days & 40 (17) & $\mathrm{Na}$ & \\
\hline
\end{tabular}

Continued

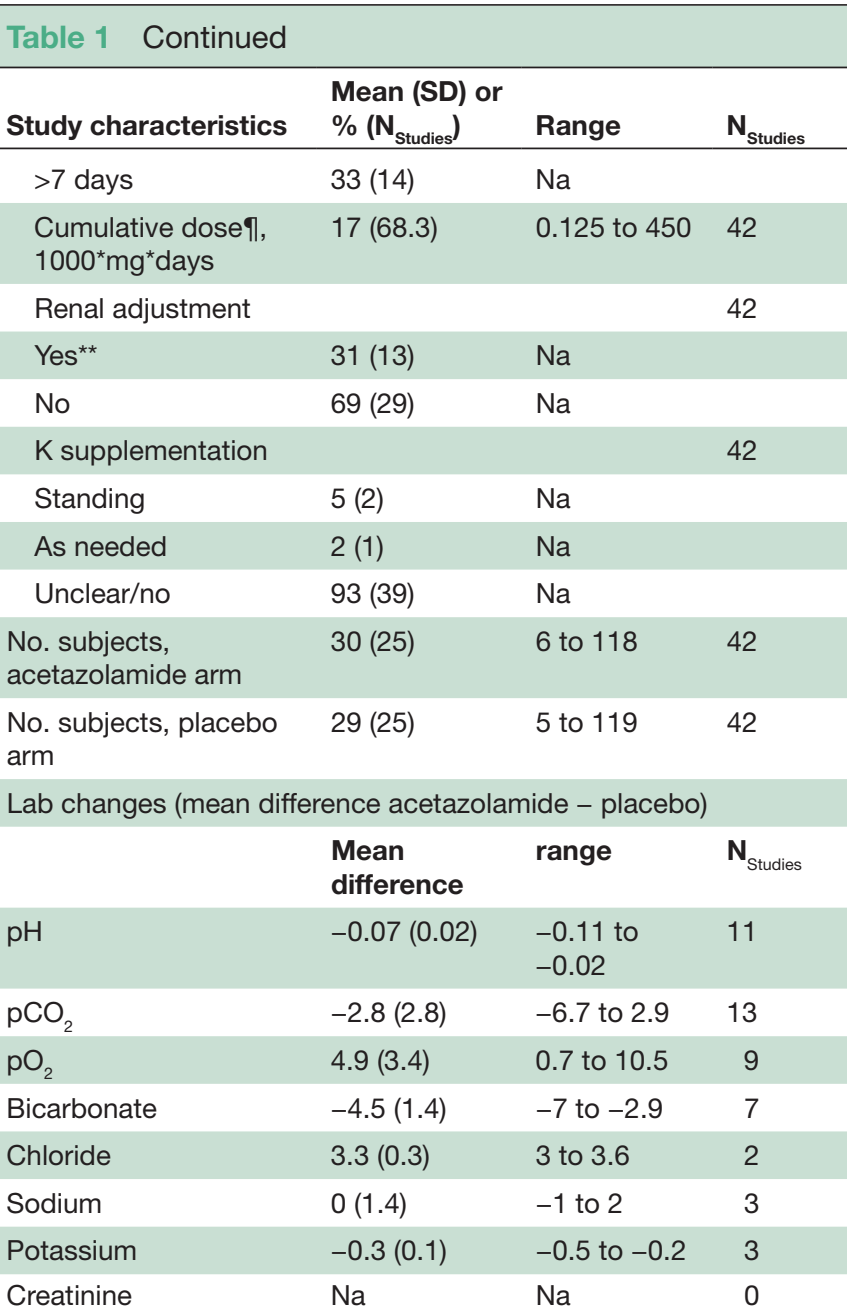

*'Other' includes refractory dysuria $(n=1)$, idiopathic intracranial hypertension $(n=1)$, post-laparoscopy pain $(n=1)$, pulmonary hypertension $(n=1)$, acute respiratory failure +metabolic alkalosis $(n=1)$, COPD $(n=2)$, migraines $(n=1)$, essential tremor $(n=1)$ and healthy volunteers $(n=2)$.

†Based on 'highest' bias across five domains (selection, performance, detection, attrition, reporting bias).

$\ddagger 40$ studies reported 'total daily dose' versus 2 reported 'total daily dose per kg'; when possible both measures were estimated using weight/BMl from the same or similar studies (data shown in this table include estimated measures).

$\S$ One trial ${ }^{29}$ escalated the total daily up to $4000 \mathrm{mg}$ if tolerated; for the analyses we used the reported mean dose of $2500 \mathrm{mg}$.

१Cumulative dose=total daily dose $x$ days of administration.

${ }^{* *}$ No study directly adjusted the acetazolamide dose based on renal function, but 13 studies either included only healthy subjects or specifically excluded subjects with renal dysfunction.

$\mathrm{BMI}$, body mass index; COPD, chronic obstructive pulmonary disease; No, Number of.

with hydrochlorothiazide or valsartan ${ }^{29}$; furthermore, two studies ${ }^{35} 47$ reported cases of metabolic acidosis but patients in both studies were hospitalised and relatively ill (acute respiratory failure or cryptococcal meningitis). Other laboratory changes reported in the literature were rare (one case of severe transaminitis ${ }^{29}$ and one case of 'hematologic dyscrasia' characterised by dropping white blood cell counts), ${ }^{29}$ but most studies did not routinely monitor blood tests. Interestingly, one study reported leuconychia in the setting of AZM plus naproxen at high 
Table 2 Risk of side effects (based on OR). Dose dependency was assessed by checking for effect modification by total daily dose and was only significant for paraesthesias and dysgeusia. There was a trend towards higher odds for fatigue, but this relationship did not reach statistical significance. ORs were chosen a priori as the effect measure for primary analyses due to the favourable mathematical properties, but to aid interpretation table 4 shows results translated into risk ratios and numbers need to treat

\begin{tabular}{|c|c|c|c|c|c|c|c|c|c|c|c|c|}
\hline \multirow[b]{2}{*}{ Side effect } & \multicolumn{2}{|c|}{ Acetazolamide } & \multicolumn{2}{|c|}{ Placebo } & \multicolumn{5}{|l|}{ Risk of side effect } & \multicolumn{3}{|c|}{$\begin{array}{l}\text { Effect modification by total daily } \\
\text { dose }(<400 \mathrm{mg} / \text { day vs } 400- \\
600 \mathrm{mg} / \text { day vs }>600 \mathrm{mg} / \text { day })\end{array}$} \\
\hline & Yes & No & Yes & No & OR $(95 \% \mathrm{Cl})$ & $\mathrm{I}^{2}(\%)$ & $\mathbf{N}$ & $\mathbf{P}_{\mathrm{OR}=1}$ & Quality $^{*}$ & Beta & $(95 \% \mathrm{Cl})$ & $\mathbf{P}_{\text {EMxTDDc }}$ \\
\hline \multicolumn{13}{|c|}{ Primary outcomes } \\
\hline Paraesthesia & 542 & 613 & 81 & 948 & 12.3 (9.3 to 16$)$ & 16 & 39 & $<0.01$ & $\begin{array}{l}\oplus \oplus \oplus \bigcirc \\
\text { Moderate }\end{array}$ & 1.8 & (1.1 to 2.9$)$ & 0.01 \\
\hline$<400 \mathrm{mg}$ & 221 & 276 & 49 & 384.5 & 8.4 (5.6 to 12.5$)$ & 10 & 13 & $<0.01$ & & & & \\
\hline $400-600 \mathrm{mg}$ & 194 & 242 & 22 & 409 & 14.5 (9.3 to 23$)$ & 11 & 20 & $<0.01$ & & & & \\
\hline$>600 \mathrm{mg}$ & 127 & 95 & 10 & 154.5 & 27.3 (12 to 63$)$ & 0 & 6 & $<0.01$ & & & & \\
\hline Dysgeusia & 84 & 729 & 10 & 625 & $4.2(2.5$ to 7.1$)$ & 0 & 22 & $<0.01$ & $\begin{array}{l}\oplus \oplus \bigcirc \bigcirc \\
\text { Low }\end{array}$ & 3.1 & (1.2 to 8.2$)$ & 0.02 \\
\hline$<400 \mathrm{mg}$ & 3 & 125 & 2 & 85.5 & 0.8 (0.18 to 3.4$)$ & 0 & 5 & 0.75 & & & & \\
\hline $400-600 \mathrm{mg}$ & 38 & 327 & 6 & 315 & 3.6 (1.8 to 7.1$)$ & 0 & 12 & $<0.01$ & & & & \\
\hline$>600 \mathrm{mg}$ & 43 & 277 & 2 & 224.5 & 9.7 (3.3 to 29$)$ & 0 & 5 & $<0.01$ & & & & \\
\hline Polyuria & 157 & 683 & 54 & 663 & 1.9 (1.3 to 2.8$)$ & 0 & 22 & $<0.01$ & $\begin{array}{l}\oplus \oplus \bigcirc \bigcirc \\
\text { Low }\end{array}$ & 1.3 & (0.7 to 2.4$)$ & 0.46 \\
\hline Fatigue & 58 & 342 & 7 & 375 & 6.5 (3.4 to 12.4$)$ & 0 & 14 & $<0.01$ & $\begin{array}{l}\oplus \oplus \bigcirc \bigcirc \\
\text { Low }\end{array}$ & 2.6 & (0.7 to 9.4$)$ & 0.14 \\
\hline \multicolumn{13}{|c|}{ Secondary outcomes } \\
\hline Nausea & 52 & 326 & 18 & 350 & 2.8 (1.6 to 4.7$)$ & 10 & 12 & $<0.01$ & & 0.8 & (0.2 to 3.5$)$ & 0.77 \\
\hline GERD & 30 & 189 & 7 & 182 & 2.8 (1.2 to 6.3 ) & 0 & 6 & 0.02 & & 2.2 & (0.6 to 8.2$)$ & 0.16 \\
\hline Diarrhoeał & 27 & 161 & 4 & 174 & 5.3 (2.1 to 13$)$ & 0 & 5 & $<0.01$ & & 1.6 & (0.01 to 397$)$ & 0.81 \\
\hline Depression & 18 & 147 & 3 & 153 & $4.2(1.5$ to 11.6$)$ & 0 & 5 & 0.01 & & 2.1 & (0.04 to 108$)$ & 0.58 \\
\hline Dizziness & 18 & 266 & 15 & 267 & 1.2 (0.6 to 2.3 ) & 0 & 10 & 0.65 & & 0.8 & (0.13 to 5.2$)$ & 0.82 \\
\hline Rash & 16 & 433 & 6 & 359 & 1.7 (0.75 to 3.8$)$ & 0 & 8 & 0.21 & & 1.8 & (0.3 to 10.4$)$ & 0.43 \\
\hline Drowsiness & 7 & 91 & 1 & 91 & $4.2(0.86$ to 21$)$ & 0 & 3 & 0.08 & & & $\mathrm{Na}+$ & \\
\hline Tinnitus & 16 & 116 & 6 & 120 & 2.5 (0.99 to 6.2 ) & 0 & 3 & 0.053 & & & Na† & \\
\hline Dyspnoea & 12 & 111 & 4 & 112 & 2.7 (0.9 to 8) & 0 & 4 & 0.07 & & & Na† & \\
\hline Dry mouth & 5 & 109 & 1 & 142 & 4.8 (0.91 to 25$)$ & 0 & 3 & 0.07 & & & $\mathrm{Na}$ & \\
\hline
\end{tabular}

${ }^{*}$ Quality of Evidence Assessment based on Grading of Recommendations Assessment, Development and Evaluation; only performed for primary outcomes (for details see online supplementary e-Table 4).

†Dose dependence was only assessed for outcomes with pooled effect estimates based on at least five studies.

fPrimary analysis for diarrhoea had a high degree of heterogeneity (OR 2.3; $95 \% \mathrm{Cl} 1.2$ to $4.4 ;\left.\right|^{2}=55 \%, n=6, p=0.01$ ) which was entirely driven by one study ${ }^{15}$ in which there were many cases of diarrhoea in the placebo group thought to be due to infectious aetiology in the setting of mountain sojourn; for the final analysis (results reported earlier) this study was excluded resulting in similar results without evidence of heterogeneity (thus final analysis is based on fixed model).

GERD, gastro-oesophageal reflux disease; $\mathrm{OR}$, Odds ratio; $\mathrm{P}_{\mathrm{EMXTDD}}, \mathrm{P}$ value for the test for effect modification by total daily dose categories; $\mathrm{P}_{\mathrm{OR}=1}, \mathrm{P}$ value for the odds ratio.

altitude. ${ }^{77}$ Furthermore, online supplementary e-Table 3 provides a qualitative summary of four studies ${ }^{70} 72-74$ that overall suggest that AZM reduces exercise tolerance and endurance (which were assessed by very different methods precluding meaningful pooling of results).

\section{DISCUSSION}

This comprehensive meta-analysis of low-to-moderate quality evidence defines the risk of common AZM side effects and corroborates the adverse effects paraesthesias, dysgeusia and possibly fatigue are dose-dependent. Severe side effects were rare and largely confined to subgroups of patients: that is, hypokalaemia almost exclusively in patients on thiazide diuretics or angiotensin-receptor blockers $^{29}{ }^{48}$ which is consistent with reports from nonincluded studies, ${ }^{14} 16$ metabolic acidosis in 'sicker' hospitalised patients, ${ }^{3547}$ dyspnoea in patients that have already an increased work of breathing due to their underlying condition ${ }^{43}$; two deaths in critically ill patients receiving AZM in the setting of underlying HIV/cryptococcal meningitis, and one case of severe transaminitis without clear risk factor. ${ }^{29}$

These data are important for a number of reasons: (1) clinical decision making is based on weighing both risks and benefits, but most published reports focus on the latter thus introducing a bias in favour of using 


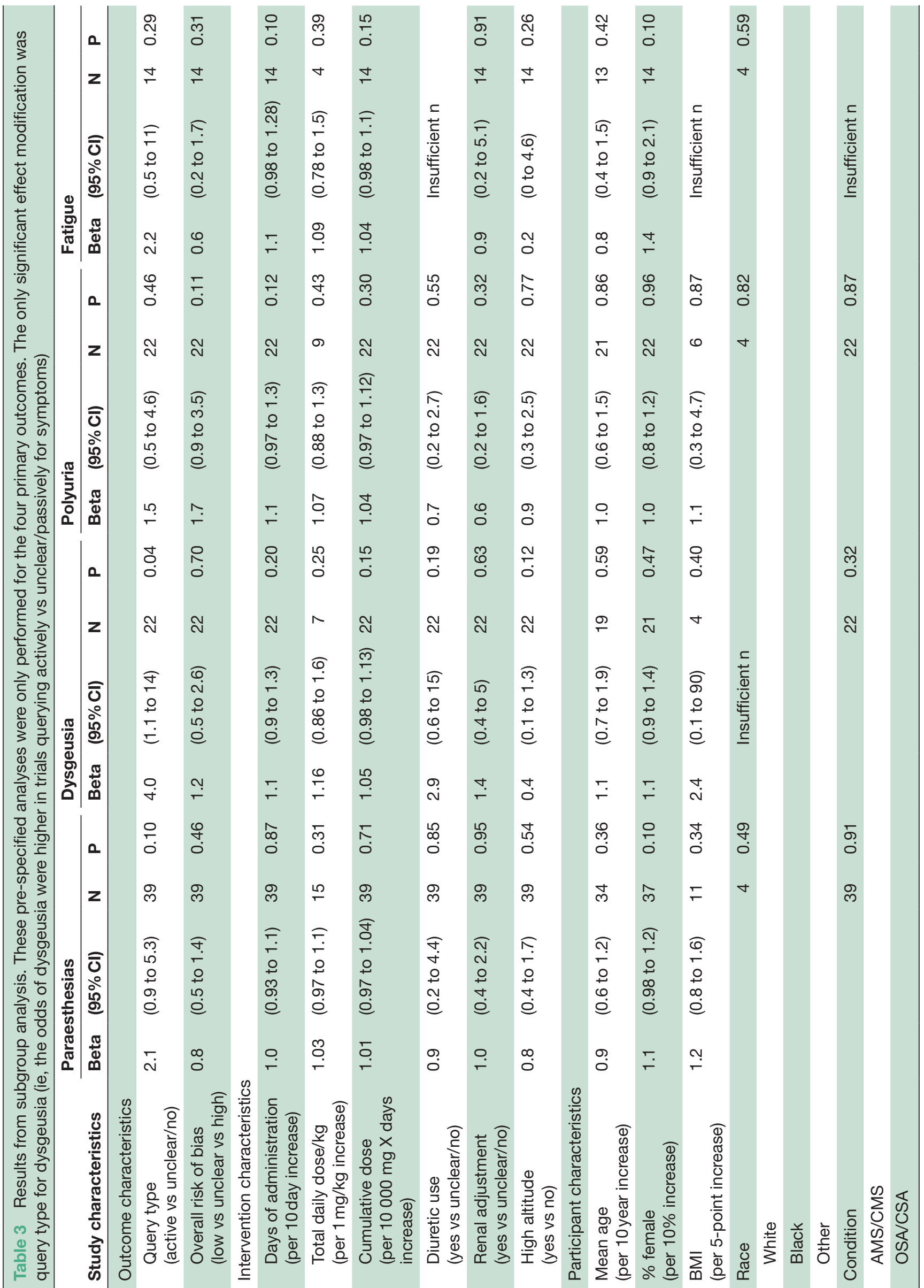


interventions. ${ }^{84} 85$ To this end our study directly complements the results of a review in the $B M J^{11}$ assessing the efficacy of AZM for preventing AMS, and enables a balanced assessment of AZM's value across the many conditions that it is being used for. (2) Our results provide guidance for clinicians about which AZM side effects may be avoidable by starting of low-dose AZM, or-once occurredmay respond to dose reduction. (3) Substantial work went into establishing the lowest effective AZM dose for preventing $\mathrm{AMS}^{114286}$; our findings validate these efforts, and more importantly provide a strong rationale to establish the lowest effective dose for other conditions as well.

Many side effects are subjective and thus vulnerable to a placebo effect as supported by the high event rates in placebo arms noted. To address this issue we restricted our review to placebo-controlled trials; nonetheless our pooled estimates for common side effects are overall very consistent with reports from observational studies. ${ }^{216}$ However, we failed to confirm effect modification by factors reported in the literature (eg, renal function, ${ }^{1921}$ weight, ${ }^{21}$ race,$^{2}$ or lab changes ${ }^{1620}$; likely reasons include frequently missing data for these covariates, low power of meta-regression in cases of few $(<10)$ included studies, risk for ecological fallacies when assessing patientlevel factors ${ }^{87}$ and the observational nature of metaregression (ie, potential for confounding). The latter issue also poses a potential threat to our findings of dose dependence for paraesthesias, dysgeusia and possibly fatigue, but our results are supported by several observations: (1) two placebo-controlled trials randomising patients to $250 \mathrm{mg}$ versus $500 / 750 \mathrm{mg}$ reported relatively more paraesthesias and dysgeusia in the higher dose AZM arm (results for polyuria were mixed; fatigue was not assessed) ${ }^{6}{ }^{42}$ (2) AZM's pharmacodynamic effects vary with dose $^{18}$ : at $1-5 \mathrm{mg} / \mathrm{kg}$ (approximately $125-350 \mathrm{mg}$ ) AZM mainly affects renal CA (resulting in a metabolic acidosis due to bicarbonate wasting with a compensatory increase in steady-state ventilation, likely a key factor for preventing $\mathrm{AMS}^{18}$ and improving SDB), ${ }^{148}$ endovascular CA (slightly increasing tissue acidosis and the arterialalveolar carbon dioxide (CO2) gradient) and peripheral chemoreceptor $\mathrm{CA}$ (reducing response rate to $\mathrm{CO} 2$ fluctuations, which may be another important mechanism through which AZM improves SDB) ${ }^{89}$ At higher doses of $7-20 \mathrm{mg} / \mathrm{kg}$ (approximately 500-1400 mg) AZM increasingly inhibits intracellular CA in non-renal tissues such as erythrocytes and the brain resulting in progressively worsening gas exchange and tissue acidosis; while these additional effects may be desirable to some degree in select patients, for example, to augment further steadystate ventilation via acidification of tissue surrounding central chemoreceptors in the brain, they likely also mediate some of the side effects. ${ }^{20}$ The fact that renal CA is fully inhibited with small doses $(<400 \mathrm{mg})$ likely explains why there is no further increase in polyuria incidence with doses beyond that. Similarly, in some but not all cases fatigue may be a result of the metabolic acidosis (secondary to bicarbonaturia due to renal CA inhibition) 
Table 4 Risk of side effects expressed as RR and NNTH

\begin{tabular}{|c|c|c|c|c|c|c|c|}
\hline \multirow[b]{3}{*}{ Side effects } & \multirow[b]{3}{*}{$\mathbf{R R}$} & \multirow[b]{3}{*}{$(95 \% \mathrm{Cl})$} & \multirow[b]{3}{*}{ NNTH } & \multirow[b]{3}{*}{$(95 \% \mathrm{Cl})$} & \multicolumn{3}{|c|}{ Event rate } \\
\hline & & & & & \multirow{2}{*}{$\begin{array}{l}\text { Placebo } \\
\%\end{array}$} & \multicolumn{2}{|c|}{ Acetazolamide* } \\
\hline & & & & & & $\%$ & (95\% Cl) \\
\hline \multicolumn{8}{|c|}{ Primary outcomes } \\
\hline Paraesthesia & 6.5 & (5.6 to 7.3 ) & 2.3 & (NNTH 2 to 2.7 ) & 7.9 & 51.4 & (44.2 to 57.7 ) \\
\hline$<400 \mathrm{mg}$ & 5.3 & (4.1 to 6.6$)$ & 2.9 & (NNTH 2.3 to 4.1 ) & 7.9 & 41.9 & (32.4 to 52.1 ) \\
\hline $400-600 \mathrm{mg}$ & 7.0 & (5.6 to 8.4$)$ & 2.1 & (NNTH 1.7 to 2.7 ) & 7.9 & 55.3 & (44.2 to 66.4$)$ \\
\hline$>600 \mathrm{mg}$ & 8.9 & (6.4 to 10.7$)$ & 1.6 & (NNTH 1.3 to 2.3 ) & 7.9 & 70.3 & (50.6 to 84.5 ) \\
\hline Dysgeusia & 4.0 & (2.4 to 6.4$)$ & 18.3 & (NNTH 10.1 to 38 ) & 1.8 & 7.2 & (4.3 to 11.5$)$ \\
\hline$<400 \mathrm{mg}$ & 0.8 & (0.2 to 3.3$)$ & NNTB 275 & (NNTH 24 to $\infty$ to NNTB 66) & 1.8 & 1.4 & (0.4 to 5.9$)$ \\
\hline $400-600 \mathrm{mg}$ & 3.4 & (1.8 to 6.4$)$ & 22.3 & (10.1 to 70.1$)$ & 1.8 & 6.1 & (3.2 to 11.5$)$ \\
\hline$>600 \mathrm{mg}$ & 8.4 & (3.2 to 19.1$)$ & 7.4 & (3 to 25) & 1.8 & 15.1 & (5.8 to 34.4$)$ \\
\hline Polyuria & 1.8 & (1.3 to 2.5$)$ & 17.0 & (NNTH 9.1 to 49 ) & 7.5 & 13.5 & (9.8 to 18.8$)$ \\
\hline Fatigue & 5.9 & (3.3 to 10$)$ & 11.1 & (NNTH 6.1 to 24 ) & 1.8 & 10.6 & (5.9 to 18$)$ \\
\hline \multicolumn{8}{|c|}{ Secondary outcomes } \\
\hline Nausea & 2.6 & (1.6 to 3.9$)$ & 13.0 & (NNTH 7 to 37 ) & 4.9 & 12.7 & (7.8 to 19.1$)$ \\
\hline GERD & 2.6 & (1.2 to 5.3$)$ & 16.6 & (NNTH 6.3 to 141 ) & 3.7 & 9.6 & (4.4 to 19.6$)$ \\
\hline Diarrhoea & 4.8 & (1.2 to 10.2$)$ & 11.6 & (NNTH 4.8 to 229) & 2.2 & 10.6 & (2.6 to 22.4$)$ \\
\hline Depression & 4.0 & (1.5 to 9.6$)$ & 17.6 & (NNTH 6 to 107 ) & 1.9 & 7.6 & (2.9 to 18.2$)$ \\
\hline Dizziness & 1.2 & (0.6 to 2.2$)$ & 100.3 & (NNTH 16.3 to $\infty$ to NNTB 49) & 5.3 & 6.4 & (3.2 to 11.7 ) \\
\hline Rash & 1.7 & (0.8 to 3.6$)$ & 89.4 & (NNTH 23 to 246) & 1.6 & 2.7 & (1.3 to 5.8$)$ \\
\hline Drowsiness & 4.1 & (0.9 to 17.3$)$ & 30.1 & (NNTH 5.7 to 663 ) & 1.1 & 4.5 & (1 to 19$)$ \\
\hline Tinnitus & 2.3 & $(1$ to 5$)$ & 15.8 & (NNTH 5.3 to 2204) & 4.8 & 11.0 & (4.8 to 24$)$ \\
\hline Dyspnoea & 2.6 & (0.9 to 6.4$)$ & 18.7 & (NNTH 5.3 to 299) & 3.4 & 8.8 & (3.1 to 21.8 ) \\
\hline Dry mouth & 4.7 & (0.9 to 21.4 ) & 38.9 & (NNTH 7 to 1599) & 0.7 & 3.3 & (0.6 to 15$)$ \\
\hline
\end{tabular}

NNTH(/NNTB), number of patients needed to be treated for one additional patient to be harmed (or benefit). ${ }^{27}$ RR and NNTH/NNTB were calculated based on odds ratio and event rate in placebo arms of included trials (see methods for details).

${ }^{*}$ Calculated as placebo event rate $\times \mathrm{RR}(95 \% \mathrm{Cl})$.

GERD, gastro-oesophageal reflux disease; $R R$, risk ratio.

possibly explaining the lack of clear dose dependence in our analysis. Support for this comes from a study in which 15 of 24 glaucoma patients with a malaise complex (including fatigue, nausea, anorexia, depression, loss of libido) experienced partial or full relieve with sodium bicarbonate to treat the underlying acidosis. ${ }^{16}$ However, while for some conditions the acidosis is just a side effect (eg, glaucoma) for others it mediates the therapeutic effect (eg, AMS) and caution is warranted as this study was uncontrolled, unblinded and changes in plasma bicarbonate levels did not predict response. Independent of dose, AZM may irritate gastric mucosa as some of the gastrointestinal side effects seem to improve when AZM is taken with food, ${ }^{16}$ which may explain lack of dose dependence for nausea in our study (although the odds of gastro-oesophageal reflux disease may increase with higher doses). (3) Our results are largely consistent with findings in two systematic reviews of AZM for the prevention of AMS, both of which only assessed a few select side effects (paraesthesia, dysgeusia, polyuria in both; rash in one) semi-quantitatively and were limited by relatively small numbers of included studies, ${ }^{11}{ }^{12}$ as well as another systematic review ${ }^{10}$ that reported similar risk of paraesthesia (but reported no data for other side effects). Another major limitation is that we may have missed some eligible studies by restricting our search query to only two databases. Regardless of this restriction several of our observations are reassuring: (1) we queried the two most widely used databases for medical research; (2) extensive review of reference lists including those from systematic reviews including other databases only revealed two additional eligible studies; (3) formal testing did not reveal significant evidence of publication bias.

Strengths of our study include meta-analyses based on large numbers of studies, evaluation of a wide range of side effects and robustness of results in extensive sensitivity analyses. One of the limitations of our study is that some of the side effects may vary over time ${ }^{6390}$; however, we did not find statistically significant effect modification by AZM duration and the primary data did not allow for a more detailed time-to-event analysis. Furthermore, one of the premises of this study was that AZM side effects can 
limit effective therapy by reducing compliance, which is likely a complex decision making process involving type of side effect, severity, efficacy but also psychosocial factors such as partner support and coping skills. ${ }^{91}$ The primary data did not allow meaningful analyses of the relationship between side effects and compliance as in most studies it was unclear if loss to follow-up or AZM discontinuation was due to a side effect. However, several observations support this notion, for example in one of the included RCTs patients with paraesthesias were 2.5 times more likely to miss AZM doses $(21 \% \text { vs } 8 \%, \mathrm{p}=0.04)^{15}$ and some studies administering AZM $500-1000 \mathrm{mg} /$ day report discontinuation rates due to side effects ranging from $26 \%$ to $35 \%$ (primarily due to fatigue and gastrointestinal symptoms rather than paraesthesias), ${ }^{2} 1648$ contrasting with another study in which only $8 \%(7 / 86)$ of patients were unable to tolerate a minimum dose of $125 \mathrm{mg}$ /day (ie, $92 \%$ were able to tolerate at least a very low dose of $125 \mathrm{mg}$ for 6 months).$^{29}$ Moreover, our study does not provide an answer as to how many patients experience any versus no side effects with AZM, because side effects tend to cluster ${ }^{20}$ and few studies report this information. In one study in which patients received a mean AZM dose of $2500 \mathrm{mg}, 83 \%$ experienced at least one side effect with a median number of side effects per person of 5 (IQR 1-22). Another potential limitation is that only one third of included studies used a cross-over (vs parallel group) design in which subjects served as their own controls. Finally, except for two studies ${ }^{354}$ of hospitalised patients, our results are based on relatively healthy subjects treated in the outpatient setting and may thus not generalise to 'sicker' populations; furthermore, based on the number of included patients in this review, our ability to detect side effects was limited to events occurring about 1/1000 patients. Similarly some side effects may be missed if they occur only in certain conditions: for example, in select patients with central sleep apnoea AZM may convert central to obstructive apnoeas with worse hypoxaemia ${ }^{92}$; in patients with reduced pulmonary reserve (eg, severe chronic obstructive pulmonary disease) AZM-induced increase in work of breathing may cause shortness of breath or even respiratory failure; in cirrhotic patients AZM may result in encephalopathy, and in subjects with reduced renal function (eg, elderly, diabetics) impaired drug clearance may result in side effects usually only seen with high-dose AZM such as severe metabolic acidosis. Also, other side effects such as nephrolithiasis (possibly responsive to citrate supplementation) or weight loss may have been under-detected due to the generally shorter observation period in randomised trials versus observational studies. More details about such potentially severe side effects in specific situations can be found in two recent reviews. ${ }^{9394}$

While this review focused on AZM, many of the findings may apply to other CA inhibitors such as methazolamide, ethoxzolamide, topiramate, zonisamide and occasionally even with topical drugs like dorzolamide.$^{93} 95$ However, CA is ubiquitous across the human body and at least 13 different isoforms of CA exist. Thus, predicting the effects of CA inhibitors is complex, ${ }^{18}{ }^{93}$ and small molecular changes between CA inhibitors may result in big differences in efficacy and side effects. Furthermore, each drug may have effects independent of CA inhibition. For example, compared with AZM, methazolamide has a similar affinity for the different CA isoforms but is more lipophilic, appears to have different effects on ventilation ${ }^{96}$ and may be better tolerated.$^{97} 98$ Nonetheless, more research is needed to assess if (and how) such differences may translate into clinical care. Such research will have to take into account the different pharmacodynamic and kinetic effects relevant to CA inhibition (eg, access of drugs to the target tissue, concentration of CA isoforms in the target tissue and the degree to which uncatalysed CA reactions contribute to the function that is targeted) ${ }^{99}$ which will differ depending on the condition of interest.

\section{CONCLUSION}

The most common side effects of AZM are paraesthesias which may reduce therapy compliance but-based on the literature-appear less likely to result in complete therapy termination than other common side effects such as fatigue and gastrointestinal symptoms. Paraesthesias, dysgeusia and possibly fatigue are likely dose-dependent phenomena and may thus be avoidable by using low-dose AZM and respond to dose reduction; on the other hand, some gastrointestinal symptoms may reflect local irritation and thus be ameliorated by administering AZM with food. In select cases, side effects may alternatively be mitigated by use of an alternative CA inhibitor or bicarbonate supplementation. Severe side effects are rare and can largely be avoided by careful patient selection (eg, hypokalaemia occurs almost exclusively in patients co-treated with thiazide diuretics or angiotensin receptor blockers). This review complements data about AZM efficacy, thus facilitating a more balanced assessment of AZM's clinical value. Observed partial dose dependence further supports efforts to establish the lowest effective AZM dose for the various conditions in which it is used (which likely rely on different pharmacodynamic effects); thus different conditions may require different doses.

Acknowledgements We would like to thank Dr Jinghong Li and Dr Kamyar Afshar for their help with evaluating two foreign language articles considered for this review.

Contributors CNS serves as guarantor and accepts full responsibility for the work and/or the conduct of the study, had access to the data and controlled the decision to publish. CNS further attests that all listed authors meet authorship criteria and that no others meeting the criteria have been omitted. CNS contributed to design, data acquisition, analysis, interpretation of the data and drafting of the manuscript. AM contributed to data acquisition, interpretation of the data and made critical revisions to the manuscript. RLO, JO and BAE contributed to interpretation of the data and made critical revisions to the manuscript.

Funding CNS is supported by the National Institutes of Health T32 grant HL134632. This study did not have any specific funding.

Competing interests CNS and J0 have nothing to declare. RLO reports personal fees from Novartis, outside the submitted work. BAE reports grants from Heart Foundation of Australia, during the conduct of the study; grants from National 
Health and Medical Research Council of Australia, other from Apnimed, outside the submitted work. As an Officer of the ATS, AM relinquished all outside personal income since 2012. ResMed provided a philanthropic donation to UC San Diego in support of a sleep centre.

Patient and public involvement Patients and/or the public were not involved in the design, or conduct, or reporting or dissemination plans of this research.

Patient consent for publication Not required.

Provenance and peer review Not commissioned; externally peer reviewed.

Data availability statement All data relevant to the study are included in the article or uploaded as supplementary information. All data are reported in e-Table

Open access This is an open access article distributed in accordance with the Creative Commons Attribution Non Commercial (CC BY-NC 4.0) license, which permits others to distribute, remix, adapt, build upon this work non-commercially, and license their derivative works on different terms, provided the original work is properly cited, appropriate credit is given, any changes made indicated, and the use is non-commercial. See: http://creativecommons.org/licenses/by-nc/4.0/.

ORCID iD

Christopher N Schmickl http://orcid.org/0000-0001-5417-9980

\section{REFERENCES}

1 Leaf A, Schwartz WB, Relman AS. Oral administration of a potent carbonic anhydrase inhibitor (diamox). I. changes in electrolyte and acid-base balance. N Engl J Med 1954;250:759-64

2 Becker B, Middleton WH. Long-Term acetazoleamide (diamox) administration in therapy of glaucomas. AMA Arch Ophthalmol 1955;54:187-92.

3 Forwand SA, Landowne M, Follansbee JN, et al. Effect of acetazolamide on acute mountain sickness. N Engl J Med 1968;279:839-45

4 White DP, Zwillich CW, Pickett CK, et al. Central sleep apnea. improvement with acetazolamide therapy. Arch Intern Med 1982;142:1816-9.

5 Wagenaar M, Vos P, Heijdra Y, et al. Comparison of acetazolamide and medroxyprogesterone as respiratory stimulants in hypercapnic patients with COPD. Chest 2003;123:1450-9.

6 Richalet J-P, Rivera M, Bouchet P, et al. Acetazolamide: a treatment for chronic mountain sickness. Am J Respir Crit Care Med 2005;172:1427-33.

7 , Wall M, McDermott MP, et al, NORDIC Idiopathic Intracranial Hypertension Study Group Writing Committee. Effect of acetazolamide on visual function in patients with idiopathic intracranial hypertension and mild visual loss: the idiopathic intracranial hypertension treatment trial. JAMA 2014;311:1641-51.

8 Mincione F, Scozzafava A, Supuran CT. The development of topically acting carbonic anhydrase inhibitors as anti-glaucoma agents. Curr Top Med Chem 2007;7:849-54.

9 Berson FG, Epstein DL, Grant WM, et al. Acetazolamide dosage forms in the treatment of glaucoma. Arch Ophthal 1980;98:1051-4.

10 Nieto Estrada VH, Molano Franco D, Medina RD, et al. Interventions for preventing high altitude illness: Part 1. Commonly-used classes of drugs. Cochrane Database Syst Rev 2017;6:Cd009761.

11 Low EV, Avery AJ, Gupta V, et al. Identifying the lowest effective dose of acetazolamide for the prophylaxis of acute mountain sickness: systematic review and meta-analysis. BMJ 2012;345:e6779.

12 Kayser B, Dumont L, Lysakowski C, et al. Reappraisal of acetazolamide for the prevention of acute mountain sickness: a systematic review and meta-analysis. High Alt Med Biol 2012;13:82-92.

13 Simancas-Racines D, Arevalo-Rodriguez I, Osorio D, et al. Interventions for treating acute high altitude illness. Cochrane Database Syst Rev 2018;6:Cd009567.

14 Edwards BA, Sands SA, Eckert DJ, et al. Acetazolamide improves loop gain but not the other physiological traits causing obstructive sleep apnoea. J Physiol 2012;590:1199-211.

15 Basnyat B, Gertsch JH, Johnson EW, et al. Efficacy of low-dose acetazolamide (125 Mg Bid) for the prophylaxis of acute mountain sickness: a prospective, double-blind, randomized, placebocontrolled trial. High Alt Med Biol 2003;4:45-52.

16 Epstein DL, Grant WM. Carbonic anhydrase inhibitor side effects. Arch Ophthal 1977:95:1378-82.

17 Alper AB, Tomlin H, Sadhwani U, et al. Effects of the selective cyclooxygenase-2 inhibitor analgesic celecoxib on renal carbonic anhydrase enzyme activity: a randomized, controlled trial. Am J Ther 2006;13:229-35.

18 Swenson ER. Carbonic anhydrase inhibitors and ventilation: a complex interplay of stimulation and suppression. Eur Respir J 1998;12:1242-7.

19 Chapron DJ, Gomolin IH, Sweeney KR. Acetazolamide blood concentrations are excessive in the elderly: propensity for acidosis and relationship to renal function. J Clin Pharmacol 1989;29:348-53.

20 Inatani M, Yano I, Tanihara H, et al. Relationship between acetazolamide blood concentration and its side effects in glaucomatous patients. J Ocul Pharmacol Ther 1999:15:97-105.

21 Yano I, Takayama A, Takano M, et al. Pharmacokinetics and pharmacodynamics of acetazolamide in patients with transient intraocular pressure elevation. Eur J Clin Pharmacol 1998;54:63-8.

22 Moher D, Liberati A, Tetzlaff J, et al. Preferred reporting items for systematic reviews and meta-analyses: the PRISMA statement. BMJ 2009;339:b2535.

23 Cui JH, Wang YH, Zhan XZ, et al. Acetozolamide and highlandvitamin-tablet for improving the recovery after exhaustion exercise at high altitude. Chinese Journal of Clinical Rehabilitation 2004;8:5100-2.

24 Sajedi P, Soleimani P. Investigating the effect of two doses of acetazolamide, as a precursor for relief of referral pain, after laparoscopic cholecystectomy with carbon dioxide gas, and comparing it with control group. Journal of Isfahan Medical School 2018;36:621-8.

25 Higgins JPT, Green S. Cochrane Handbook for systematic reviews of interventions version 5.1.0, 2019. www.handbook.cochrane.org

26 Friedrich JO, Adhikari NKJ, Beyene J. Inclusion of zero total event trials in meta-analyses maintains analytic consistency and incorporates all available data. BMC Med Res Methodol 2007;7:5.

27 Altman DG. Confidence intervals for the number needed to treat. BMJ 1998;317:1309-12.

28 Higgins JPT, Thompson SG, Deeks JJ, et al. Measuring inconsistency in meta-analyses. BMJ 2003;327:557-60.

29 ten Hove MW, Friedman DI, Patel AD, et al. Safety and tolerability of acetazolamide in the idiopathic intracranial hypertension treatment trial. J Neuroophthalmol 2016;36:13-19.

30 Sharma S, Gralla J, Ordonez JG, et al. Acetazolamide and Nacetylcysteine in the treatment of chronic mountain sickness (Monge's disease). Respir Physiol Neurobiol 2017;246:1-8.

31 Hamidi M, Aghamir SMK, Salavati A, et al. A pilot randomized study on use of oral acetazolamide in patients with refractory dysuria. Int Urol Nephrol 2017;49:927-30.

32 Bala I, Bhatia N, Mishra P, et al. Comparison of preoperative oral acetazolamide and intraperitoneal normal saline irrigation for reduction of postoperative pain after laparoscopic cholecystectomy. $J$ Laparoendosc Adv Surg Tech A 2015;25:285-90.

33 Ulrich S, Keusch S, Hildenbrand FF, et al. Effect of nocturnal oxygen and acetazolamide on exercise performance in patients with pre-capillary pulmonary hypertension and sleep-disturbed breathing: randomized, double-blind, cross-over trial. Eur Heart $J$ 2015;36:615-23.

$34 \mathrm{Ke} \mathrm{T}$, Wang J, Swenson ER, et al. Effect of acetazolamide and gingko biloba on the human pulmonary vascular response to an acute altitude ascent. High Alt Med Biol 2013;14:162-7.

35 Gulsvik R, Skjørten I, Undhjem K, et al. Acetazolamide improves oxygenation in patients with respiratory failure and metabolic alkalosis. Clin Respir J 2013;7:390-6.

36 Wang J, Ke T, Zhang X, et al. Effects of acetazolamide on cognitive performance during high-altitude exposure. Neurotoxicol Teratol 2013;35:28-33.

37 Latshang TD, Nussbaumer-Ochsner Y, Henn RM, et al. Effect of acetazolamide and AutoCPAP therapy on breathing disturbances among patients with obstructive sleep apnea syndrome who travel to altitude. JAMA 2012;308:2390-8.

38 Nussbaumer-Ochsner Y, Latshang TD, Ulrich S, et al. Patients with obstructive sleep apnea syndrome benefit from acetazolamide during an altitude sojourn: a randomized, placebo-controlled, double-blind trial. Chest 2012;141:131-8.

39 van Patot MCT, Leadbetter G, Keyes LE, et al. Prophylactic low-dose acetazolamide reduces the incidence and severity of acute mountain sickness. High Alt Med Biol 2008;9:289-93.

40 Richalet J-P, Rivera-Ch M, Maignan M, et al. Acetazolamide for Monge's disease: efficiency and tolerance of 6-month treatment. Am $J$ Respir Crit Care Med 2008;177:1370-6.

41 Hillenbrand P, Pahari AK, Soon Y, et al. Prevention of acute mountain sickness by acetazolamide in Nepali porters: a double-blind controlled trial. Wilderness Environ Med 2006;17:87-93.

42 Basnyat B, Gertsch JH, Holck PS, et al. Acetazolamide 125 Mg BD is not significantly different from $375 \mathrm{Mg} B D$ in the prevention of 
acute mountain sickness: the prophylactic acetazolamide dosage comparison for efficacy (PACE) trial. High Alt Med Biol 2006;7:17-27.

43 Javaheri S. Acetazolamide improves central sleep apnea in heart failure: a double-blind, prospective study. Am J Respir Crit Care Med 2006;173:234-7.

44 Chow T, Browne V, Heileson HL, et al. Ginkgo biloba and acetazolamide prophylaxis for acute mountain sickness: a randomized, placebo-controlled trial. Arch Intern Med 2005;165:296-301.

45 Gertsch JH, Basnyat B, Johnson EW, et al. Randomised, double blind, placebo controlled comparison of Ginkgo biloba and acetazolamide for prevention of acute mountain sickness among Himalayan trekkers: the prevention of high altitude illness trial (PHAIT). BMJ 2004;328:797.

46 Fischer R, Lang SM, Leitl M, et al. Theophylline and acetazolamide reduce sleep-disordered breathing at high altitude. Eur Respir $J$ 2004;23:47-52.

47 Newton PN, Thai LH, Tip NQ, et al. A randomized, double-blind, placebo-controlled trial of acetazolamide for the treatment of elevated intracranial pressure in cryptococcal meningitis. Clin Infect Dis 2002;35:769-72.

48 Vahedi K, Taupin P, Djomby R, et al. Efficacy and tolerability of acetazolamide in migraine prophylaxis: a randomised placebocontrolled trial. J Neurol 2002;249:206-11.

49 Gunal DI, Afșar N, Bekiroglu N, et al. New alternative agents in essential tremor therapy: double-blind placebo-controlled study of alprazolam and acetazolamide. Neurol Sci 2000;21:315-7.

50 Moldow B, Sander B, Larsen M, et al. The effect of acetazolamide on passive and active transport of fluorescein across the Blood-Retina barrier in retinitis pigmentosa complicated by macular oedema. Graefes Arch Clin Exp Ophthalmol 1998;236:881-9.

51 Ladas IDet al. Topical $2.0 \%$ dorzolamide vs oral acetazolamide for prevention of intraocular pressure rise after neodymium:YAG laser posterior capsulotomy. Arch Ophthal 1997;115:1241-4.

52 Whitcup SM, Csaky KG, Podgor MJ, et al. A randomized, masked, cross-over trial of acetazolamide for cystoid macular edema in patients with uveitis. Ophthalmology 1996;103:1054-63.

53 Vos PJ, Folgering HT, de Boo TM, et al. Effects of chlormadinone acetate, acetazolamide and oxygen on awake and asleep gas exchange in patients with chronic obstructive pulmonary disease (COPD). Eur Respir J 1994;7:850-5.

54 Farber MD, Lam S, Tessler HH, et al. Reduction of macular oedema by acetazolamide in patients with chronic iridocyclitis: a randomised prospective crossover study. $\mathrm{Br} \mathrm{J}$ Ophthalmol 1994:78:4-7.

55 Ladas ID, Pavlopoulos GP, Kokolakis SN, et al. Prophylactic use of acetazolamide to prevent intraocular pressure elevation following Nd-YAG laser posterior capsulotomy. Br J Ophthalmol 1993;77:136-8.

56 Grissom CKet al. Acetazolamide in the treatment of acute mountain sickness: clinical efficacy and effect on gas exchange. Ann Intern Med 1992;116:461-5.

57 Fishman GAet al. Acetazolamide for treatment of chronic macular edema in retinitis pigmentosa. Arch Ophthal 1989;107:1445-52.

58 Metcalfe TW, Etchells DE. Prevention of the immediate intraocular pressure rise following argon laser trabeculoplasty. $\mathrm{Br} \mathrm{J}$ Ophthalmol 1989;73:612-6.

59 Whyte KF, Gould GA, Airlie GA, et al. Role of protriptyline and acetazolamide in the sleep apnea/hypopnea syndrome. Sleep 1988;11:463-72.

60 Häcki MA, Waldeck G, Brändli O. [Acetazolamide in hypercapnic chronic obstructive lung disease--a renaissance?]. Schweiz Med Wochenschr 1983;113:110-4.

61 Larson EB, Roach RC, Schoene RB, et al. Acute mountain sickness and acetazolamide. clinical efficacy and effect on ventilation. JAMA 1982;248:328-32.

62 Greene MK, Kerr AM, McIntosh IB, et al. Acetazolamide in prevention of acute mountain sickness: a double-blind controlled cross-over study. BMJ 1981;283:811-3.

63 BMRESMSSG. Acetazolamide in control of acute mountain sickness. Lancet 1981;1:180-3.

64 Collier DJ, Wolff CB, Hedges A-M, et al. Benzolamide improves oxygenation and reduces acute mountain sickness during a highaltitude TREK and has fewer side effects than acetazolamide at sea level. Pharmacol Res Perspect 2016;4:e00203-12.

65 Reinhart WH, Goerre S, Bärtsch P. Acetazolamide reduces the erythropoietin response to hypoxia at high altitude in humans. $J$ Wilderness Med 1994;5:312-7.

66 Rosenbaek JB, Pedersen EB, Bech JN. The effect of sodium nitrite infusion on renal function, brachial and central blood pressure during enzyme inhibition by allopurinol, enalapril or acetazolamide in healthy subjects: a randomized, double-blinded, placebo-controlled, crossover study. BMC Nephrol 2018;19.

67 Utz G, Schlierf G, Barth P, et al. [Prevention of acute mountain sickness using acetazolamide]. Munch Med Wochenschr 1970;112:1122-4.

68 Zell SC, Goodman PH. Acetazolamide and dexamethasone in the prevention of acute mountain sickness. West $\mathrm{J}$ Med 1988; $148: 541-5$

69 Faull OK, Robertson J, Thomas O, et al. The effect of acetazolamide on saccadic latency at 3459 meters. Wilderness Environ Med 2015;26:72-7.

70 Bradwell AR, Myers SD, Beazley M, et al. Exercise limitation of acetazolamide at altitude (3459 M). Wilderness Environ Med 2014;25:272-7.

71 Lalande S, Snyder EM, Olson TP, et al. The effects of sildenafil and acetazolamide on breathing efficiency and ventilatory control during hypoxic exercise. Eur J Appl Physiol 2009;106:509-15.

72 Faoro V, Huez S, Giltaire S, et al. Effects of acetazolamide on aerobic exercise capacity and pulmonary hemodynamics at high altitudes. $J$ Appl Physiol 2007;103:1161-5.

73 Fulco CS, Muza SR, Ditzler D, et al. Effect of acetazolamide on leg endurance exercise at sea level and simulated altitude. Clin Sci 2006;110:683-92.

74 Garske LA, Brown MG, Morrison SC. Acetazolamide reduces exercise capacity and increases leg fatigue under hypoxic conditions. J Appl Physiol 2003;94:991-6.

75 Brechue WF, Koceja DM, Stager JM. Acetazolamide reduces peripheral afferent transmission in humans. Muscle Nerve 1997;20:1541-8.

76 Leys MJJ, van Slycken S, Nork TM, et al. Acetazolamide affects performance on the Nagel II anomaloscope. Graefes Arch Clin Exp Ophthalmol 1996;234:S193-7.

77 Burtscher M, Likar R. Leukonychia following high altitude exposure. High Alt Med Biol 2002;3:93-4.

78 Bradwell AR, Delamere JP, Mackintosh JH. Acetazolamide in the mountains. The Lancet 1981;317:730.

79 Nicholson AN, Smith PA, Stone BM, et al. Altitude insomnia: studies during an expedition to the Himalayas. Sleep 1988;11:354-61.

80 Kronenberg RS, Cain SM. Effects of acetazolamide on physiologic and subjective responses of men to 14,000 feet. SAM-TR-67-81. Tech Rep SAM-TR 1967:1-10.

81 Sansone VA, Burge J, McDermott MP, et al. Randomized, placebocontrolled trials of dichlorphenamide in periodic paralysis. Neurology 2016;86:1408-16.

82 Schneider-Gold C, Schoser B, Ellrichmann G, et al. Guideline myotonic dystrophies, Non-Dystrophic myotonias and periodic paralyses. Aktuelle Neurologie 2018;45:167-77.

83 Hackett PH, Rennie D, Levine HD. The incidence, importance, and prophylaxis of acute mountain sickness. Lancet 1976;2:1149-55.

84 Wise J. Side effects are under-reported in peer reviewed journals. BMJ 2016;354:i5075.

85 Zorzela L, Golder S, Liu Y, et al. Quality of reporting in systematic reviews of adverse events: systematic review. $B M$ 2013;348:f7668

86 Carlsten C, Swenson ER, Ruoss S. A dose-response study of acetazolamide for acute mountain sickness prophylaxis in vacationing tourists at 12,000 feet $(3630 \mathrm{M})$. High Alt Med Biol 2004:5:33-9.

87 da Costa BR, Jüni P. Systematic reviews and meta-analyses of randomized trials: principles and pitfalls. Eur Heart $J$ 2014:35:3336-45.

88 Sakamoto T, Nakazawa Y, Hashizume Y, et al. Effects of acetazolamide on the sleep apnea syndrome and its therapeutic mechanism. Psychiatry Clin Neurosci 1995;49:59-64.

89 Javaheri S, Sands SA, Edwards BA. Acetazolamide attenuates Hunter-Cheyne-Stokes breathing but augments the hypercapnic ventilatory response in patients with heart failure. Ann Am Thorac Soc 2014;11:80-6.

90 Dahl H, Norskov K, Peitersen E, et al. Zinc therapy of ACETAZOLAMIDE-INDUCED side-effects. Acta Ophthalmol 1984;62:739-45.

91 Crawford MR, Espie CA, Bartlett DJ, et al. Integrating psychology and medicine in CPAP adherence - new concepts? Sleep Med Rev 2014:18:123-39.

92 Sharp JT, Druz WS, D'Souza V, et al. Effect of metabolic acidosis upon sleep apnea. Chest 1985;87:619-24.

93 Swenson ER. Safety of carbonic anhydrase inhibitors. Expert Opin Drug Saf 2014;13:459-72.

94 Adamson R, Swenson ER. Acetazolamide use in severe chronic obstructive pulmonary disease. pros and cons. Ann Am Thorac Soc 2017; 14:1086-93. 
95 Hoffmanová I, Sánchez D. Metabolic acidosis and anaemia associated with dorzolamide in a patient with impaired renal function. Br J Clin Pharmacol 2018;84:796-9.

96 Teppema LJ, Swenson ER. The noncarbonic anhydrase inhibiting acetazolamide analog $N$-methylacetazolamide reduces the hypercapnic, but not hypoxic, ventilatory response. Physiol Rep 2015;3:e12484.
97 Lichter PR, Newman LP, Wheeler NC, et al. Patient tolerance to carbonic anhydrase inhibitors. Am J Ophthalmol 1978;85:495-502.

98 Lichter PR. Reducing side effects of carbonic anhydrase inhibitors. Ophthalmology 1981;88:266-9.

99 Maren TH. The relation between enzyme inhibition and physiological response in the carbonic anhydrase system. J Pharmacol Exp Ther 1963;139:140-53. 